\title{
Dios en el pensamiento posmoderno: Hacia una teología de la muerte o de la afirmación de la vida
}

Claudio H. Pérez B.*

\author{
Recibido: Julio 2011 • Aceptado: Setiembre 2011
}

\section{RESUMEN}

En este ensayo se busca una aproximación al pensamiento que la posmodernidad tiene de Dios. El autor reconoce las dificultades del tema. Sin embargo, se ha hecho posible abordarlo utilizando datos cuantitativos, que ofrecen una imagen de Dios. También se explora en forma introductoria la dimensión de la apertura a lo trascendente. Finalmente, el autor desea ofrecer elementos que ayuden a la sanación espiritual del hombre posmoderno.

Palabras clave: Dios, religión, Posmodernidad, Método cuantitativo, Apertura a lo trascendente, Sanación espiritual.

\section{ABSTRACT}

In this essay, it is been tried to an approximation of the post-modernity thought about God. The author recognizes the difficulties of the topic. However, it has become impossible to treat it using quantity facts, which offer an image of God. Also, it is been explored in an introductory way to the dimension of the opening to the transcendent. Finally, the author wishes to offer elements that help to the spiritual healing to the post-modern man.

Key words: God, religion, Post-modernity, quantity method, opening to the transcendent, spiritual healing.

* Tiene un Bachillerato en Ciencias teológicas por la Universidad Bíblica Latinoamericana y una Maestría en Teología de la Universidad Estatal a Distancia (UNED), Costa Rica. Actualmente se desempeña como instructor de Teología en Osorno, Chile. 


\section{Introducción}

"Pero cuando el Hijo del hombre venga, ¿encontrará todavía fe en la tierra? Jesucristo (S. Lucas 18: 8, DHH)

En la presente investigación intento realizar una aproximación al pensamiento que la posmodernidad tiene de Dios, tanto en el contexto mundial, en general, como en el contexto de América Latina, en particular.

Reconozco el amplio grado de dificultad que posee el referido tema, ya que en la actualidad no es posible, hasta donde lo he podido verificar, encontrar una exposición sistemática del pensamiento y/o conceptualización que la posmodernidad posee sobre Dios. Estamos frente a una realidad del todo fragmentaria, diversa, dispersa y llena de múltiples contradicciones que, sin inconvenientes se puede decir que es una realidad de "crisis" (Roa, 1991: 61), donde las situaciones humanas se van produciendo prácticamente de forma inconciente, sin para nada detenerse a sistematizar sobre tal o cual asunto. Es que los grandes relatos han sido superados, y con lo mismo Dios ha quedado relegado al pasado, llegándose a evaporar, debido a su naturaleza esencialmente "líquida" (Vásquez, 2008), tal como lo plantea Zygmunt Bauman, cuestión que es parte esencial y constituyente, no solo en el tema de Dios, sino también de las diversas temáticas que fluyen en el contexto de la posmodernidad.

De acuerdo con lo anterior, y asumiendo las limitaciones intrínsecas que tal ejercicio demanda, en la actualidad se hace posible trabajar con datos de carácter cuantitativos, que por lo demás se han incrementado notablemente en su producción, permitiendo esto una aproximación a la realidad, en nuestro caso concreto, al pensamiento que la posmodernidad posee sobre Dios. En este sentido destaca la Gallup International Millennium Survey (Carballo), que recoge los resultados de 60 países, representando 1250 millones de personas en el mundo. Además, se agregan otras encuestas realizadas, esencialmente en el suelo Latinoamericano. Esto último, y de manera más específica, con el propósito de acercarse a un diagnóstico sobre el tema de Dios y la religión en nuestro continente. Claro está, que la cuestión sobre si América Latina es o no posmoderna, es un asunto que ya se viene discutiendo por muchos años, y todo/a lector/a medianamente versado/a sobre el tema, se dará cuenta de la magnitud del debate. Si bien ciertos autores consideran a América Latina como posmoderna, algunos derechamente no lo ven así, y otros observan un verdadero cruce de realidades disímiles. A este 
respecto me parece pertinente citar las palabras de In Sik Hong, que se orienta en el ámbito del análisis contextual de la realidad.

En esta instancia podemos concluir que la posmodernidad en América Latina no es la misma que la europea. El debate y la compresión de tal posmodernidad deben partir del contexto peculiar del continente latinoamericano, es decir, de 1) la heterogeneidad multitemporal de su cultura; 2) la perspectiva histórica de su incorporación en la experiencia de la modernidad; y 3) la perspectiva histórica de su lucha en busca de espacios para ser hombres libres (2001: 25).

Si bien, y de acuerdo con lo anterior, las aproximaciones sociológicas han ganado su lugar y han hecho sus aportes a los ingentes estudios de la vida humana, considero que la teología (pero no dejando de lado las demás ciencias, sino más bien valiéndose de ellas para profundizar en sus consideraciones), está en el deber de referirse a la situación de la posmodernidad en el mundo y en América Latina de forma especial, pero no con una referencia de carácter general, de las cuales ya existen muchas, sino más bien respecto al tema de Dios, a su concepción, a su vivencia, en fín, a la imagen que existe de Dios en el pensamiento posmoderno. $\mathrm{Y}$ esto precisamente nos lo proporcionan, por ahora, los resultados de las encuestas que expondré más adelante.
Además, debo agregar, si bien la posmodernidad, esencialmente desde la mirada de la teología cristiana, ha sido vista con cierta conmiseración por los efectos que estimula en la vida de los seres humanos (así lo confirman gran cantidad de trabajos realizados), me ha parecido en la presente investigación, y desde la perspectiva fenomenológica, explorar introductoriamente la dimensión de apertura a lo trascendente a la que nos invita la posmodernidad. Así, y reconociendo aún las limitaciones del presente trabajo, intento realizar una aproximación, al menos integral, de tan compleja materia de estudio, como lo es Dios en el pensamiento posmoderno.

Así, además de los recurrentes datos y análisis que serán expuestos, la presente investigación lo que busca es presentar un camino que pueda orientar al ser humano posmoderno dentro de su gran realidad de crisis existencial, pudiéndole ofrecer algo que efectivamente contribuya a su sanación espiritual, y que además fortalezca a quienes tienen el mayor privilegio de sentirse amados y de amar al Dios que se constituye en causa, trayectoria y fin último de sus existencias.

\section{América Latina: Posmoderna?}

El destacado investigador, George Yúdice, especialista en 
cuestiones culturales de América Latina, publicó en el año 1989, en la Revista de Crítica Literaria Latinoamericana, un artículo que en su título planteaba una interrogante, que a mi juicio aún está en proceso de ser respondida, y que por lo demás ha provocado las más variadas reacciones y análisis de gran cantidad de especialistas. La referida interrogante decía: ¿Puede hablarse de posmodernidad en América Latina? (105). Claro está que esta pregunta, por un lado, se niega a aceptar la calificación común que se da sobre la posmodernidad como una realidad omniabarcante en las actuales sociedades del mundo y, por otro lado, invita a reflexionar y a replantearse, me parece, el significado de lo que es la posmodernidad. En este contexto, considero que el aporte de George Yúdice consiste fundamentalmente en problematizar sobre una realidad que se ha hecho por demás común $\mathrm{y}$, por lo tanto, tema superficial en el momento de su puesta en discusión. De acuerdo con lo anterior, no resulta para nada fácil emitir un juicio de carácter categórico cuando nos aproximamos a considerar la realidad de América Latina en el contexto de la posmodernidad.

En el mencionado artículo, Yúdice hace referencia a tres destacados autores (Juan Corradi, Carlos Waisman y Andrés Avellaneda) que coinciden en cuanto a que
Argentina, pudiendo esto en parte ser representativo de América Latina, no puede ser considerada posmoderna. De acuerdo con lo anterior, no debe olvidarse que el referido trabajo de George Yúdice ya ha sobrepasado los 20 años, y que en la actualidad la situación latinoamericana se puede considerar en ciertos aspectos distinta a lo que era hace dos décadas. Así, y a manera de enfrentar a dos importantes investigadores, considero pertinente destacar la fresca conceptualización que Roberto Follari hace del tema, diciendo que "lo posmoderno, -creo que puede afirmarse plausiblemente- no constituye ya aquello de lo que se habla, justamente porque pasó a ser el lugar desde el cual se habla" (2010: 54), así, Follari, además indica decididamente que "lo posmoderno se plasmó en Latinoamérica a partir de mediados de los años ochentas" (53).

Las opiniones anteriores, tanto de George Yúdice como de Roberto Follari, presentan de manera evidente una clara oposición, que para nada carecen de una debida fundamentación conceptual del tema. Ahora, planteada la referida problemática, se hace urgentemente necesario (y lo indico desde una orientación claramente epistemológica) emitir criterios que nos permitan tomar una postura sobre la realidad latinoamericana en el contexto de la posmodernidad. 
Admito que lo anterior no es una tarea fácil, ya que está revestida de una alta complejidad hermenéutica, y que por tal razón, me parece, no resulta para nada cómodo emitir criterios con ligereza que determinen o juzguen tal o cual situación. En este marco, considero que frente al gran caudal de opiniones y juicios existentes sobre la temática de la posmodernidad, la aproximación del teólogo mexicano Daniel Chiquete permite acercarse al tema de una manera no habitualmente recurrente. Chiquete agrega lo siguiente:

Creo que si el prefijo "pos" se refiere a la superación de la modernidad, habría que especificar a qué modernidad se refiere. Si se piensa en la modernidad occidental, se debe diferenciar al menos entre los modelos europeo, norteamericano y latinoamericano. Además, referida a América Latina, surge el problema de hablar de posmodernidad en paises que ni siquiera entraron a la modernidad, o que pueden ser en algunas áreas modernos, en otras posmodernos y en otras, incluso, premodernos. Yo prefiero renunciar a ofrecer una definición más $y$ me conformo con señalar que con el concepto "posmodernidad" me refiero al conjunto de situaciones surgidas con los procesos de globalización o mundialización de la economía neoliberal, el repunte de las tendencias secularizantes en las sociedades occidentales, la implementación e impacto de las nuevas tecnologías comunicativas, los cambios geopolíticos posteriores al fin de la guerra fría, la crisis de los paradigmas en la filosofia, las ciencias y las artes y la aparición o reaparición de diversas formas de expresiones religiosas (2006: 219, 220).

En lo anterior, Chiquete deja ver la gran complejidad que lleva consigo el poder precisar qué zona del planeta se ajusta al estándar de lo que se ha llegado a llamar posmodernidad, ya que es una situación absolutamente inseparable de la realidad humana insertada en su contexto particular íntegro que, por supuesto, está plenamente condicionada por las peculiaridades y características propias (y podría decir hasta requisitos) de los diversos conglomerados humanos. Además, cabe destacar, y para los fines de la presente investigación, el acercamiento que Chiquete realiza a la posmodernidad al referirse a Latinoamérica, junto con sus vertiginosos cambios sociales y religiosos; sobre esto dice:

The speed of change in the world over the last few decades has been echoed by an equally rapid transformation on the religious scene in Latin America. The two processes are related to each other and affect each other in some respects, although they are completely independent in others. The religious component of 
Latin American identity is so much part of social identity that any change in social relations or behaviour is directly reflected in the field of religión (2003: 29).

Y es precisamente aquí donde, considero, debe ser retomada la pregunta inicial planteada en nuestro apartado, y también por George Yúdice, ¿Puede hablarse de posmodernidad en América Latina? Si para responder a esta interrogante (por supuesto que aproximándonos desde una perspectiva hasta ahora general), invocamos a los tres mencionados especialistas, nos podemos quedar sin respuesta, sin embargo, considero que nos encontramos frente a una realidad de carácter "ambivencial" (a manera de neologismo), cuestión que expresa su intrínseca complejidad, y que al reconocerla como tal, sí es posible emitir un criterio, permite permite decir que América Latina SÍ se identifica con la posmodernidad; y también que América Latina NO se identifica con la posmodernidad. En este contexto, es posible hablar de una sociedad latinoamericana sumida en la crisis, y por otro lado ajena a la crisis. Entonces América Latina SÍ es posmoderna y NO es posmoderna. Ambas realidades, y de forma simultánea, claramente viven y conviven en nuestro universo humano. Así, me parece que la afirmación y la negación (contradictoriamente) simultáneas no son otra cosa que la clara "ambigüedad" (219) inherente de la posmodernidad.

Así, todo lo anterior nos prepara para aproximarnos al gran tema de Dios en el pensamiento posmoderno, que necesariamente colocará su atención en el contexto latinoamericano en particular, y del mundo en general.

\section{Dios en el pensamiento posmoderno}

Expresar el pensamiento que la posmodernidad posee sobre Dios, no es una cuestión del todo sencilla, considerando, por una parte, que el análisis será siempre limitado, ya que se realiza desde el cristianismo como referente de juicio $y$, por el otro, debido a la naturaleza inmensamente compleja, ambigua, paradójica y contradictoria de la posmodernidad. De acuerdo con lo anterior, e intentando ofrecer una definición del término mentalidad secular (posmodernidad), el Dr. Juan Carlos Viera, destacado misionólogo adventista, dice que es "más prudente describirlo que definirlo" (1990: 133). Precisamente es eso lo que configura la cuestión sobre Dios en el pensamiento posmoderno, al esto significa que no es posible hablar de Dios en la posmodernidad desde una realidad sistemática o finalmente elaborada, por ejemplo, o de encontrar un 
apartado propio y exclusivo sobre el tema de Dios, por supuesto, no del ámbito de la crítica y análisis valórico, sino en el contexto de la exposición legítima que el propio pensamiento posmoderno pueda ofrecer en relación con el tema en cuestión. Así, lo que hoy está al alcance para una aproximación como la que intento realizar, es abordar el asunto desde una perspectiva más abarcante, que considera la religión, y por ende a Dios, como expresión humana ya cruzada por la concepción posmoderna.

Para tal efecto, he decidido recurrir como instrumento de diagnóstico de la religión en el contexto de la posmodernidad, a la exposición y análisis de datos cuantitativos, que me parece resultarán de gran orientación en este sentido. Se trata, en primer lugar, de la encuesta Millennium, de Gallup International, publicada a fines de 1999, y que "fue realizada en setenta países y representa las opiniones de 1250 millones de adultos, esto es, un cuarto de la población mundial" (Pereyra y Espinosa, 2000: 43, 44). En segundo lugar, presentaré información de países latinoamericanos, con la clara intencionalidad de profundizar en la realidad religiosa de nuestro continente.

\section{Resultados de la encuesta Millennium, de Gallup International}

La encuesta fue publicada por la presidenta de Gallup Argentina y miembro del Board de Gallup International, Marita Carballo. Fueron incluidos datos mundiales acompañados con los de Argentina. Estos últimos pueden ser considerados como representativos de otros países de Sudamérica. Se consideraron cinco variables fundamentales de la religiosidad, que permiten considerar cómo se entiende y vive la relación con Dios.

Las cinco variables fueron las siguientes $(44,45,46)$ :

1.1. Pertenencia a una confesión.

- El $\mathbf{8 7 \%}$ del total de la población mundial dijo pertenecer a algún tipo de denominación.

- El $13 \%$ no adhirió a ninguna confesión.

- El puntaje más alto fue en África con el $\mathbf{9 9 \%}$.

- El más bajo fue en el sudeste asiático, con un $\mathbf{7 7 \%}$.

- En Argentina, el 93\% afirmó pertenecer a alguna religión, la mayoría se identificó con la Iglesia Católica. 
Se encontró que a medida que aumenta el nivel socioeconómico y educativo de la gente disminuye la pertenencia religiosa.

\subsection{Práctica del culto.}

- Sólo un 32\% del total mundial señaló que asiste a los servicios religiosos, por lo menos una vez por semana.

- $\quad$ El 35\% lo hace esporádicamente.

- El 33\% no practica nunca o casi nunca.

- El 90\% de los africanos son practicantes.

- $\quad$ El 70\% de los practicantes se ubica en América Latina.

- Los que no practican nunca o casi nunca son los europeos occidentales, con un $\mathbf{4 8} \%$, y los orientales con un $\mathbf{4 4} \%$.

- Asisten más regularmente las mujeres, con un $35 \%$, que los varones, con un $\mathbf{2 8} \%$.

- Los de estudios primarios asisten un $\mathbf{3 3} \%$, en relación conlos de estudios universitarios que asisten un $\mathbf{2 5 \%}$. Son más practicantes los menores de 24 años.

- En Argentina, solamente el $\mathbf{2 7} \%$ asiste regularmente a la iglesia una vez por semana y el $\mathbf{3 5} \%$ no va nunca o casi nunca.

1.3. Importancia de Dios en la vida. Para medir esta dimensión se utilizó una escala de importancia que variaba entre 1 (ninguna importancia) y 10 (máxima importancia).

- Promediando las opiniones se encontró un puntaje de 7,2 a nivel mundial. Esto significa que existe un alto nivel de consideración de Dios en la experiencia personal de la gente.

- El 63\% de la población le atribuyó mucha o bastante importancia (entre 7 a 10 puntos).

- El 16\% se ubicó en posiciones intermedias ( 5 a 6 ).

- El 21\% le asignó poca o ninguna importancia (1 a 4).

- Se detectó gran importancia en África, el 97\%.

- La importancia en América Latina fue de un $\mathbf{8 8} \%$.

- La importancia en América del Norte fue de un $\mathbf{8 2} \%$.

- En el sudeste asiático y Europa fue de un $\mathbf{4 8} \%$.

- En Argentina, el promedio de importancia asignada a Dios en la vida personal fue muy alto, alanzando la cifra de $\mathbf{0} \%$.

1.4. Fe en una divinidad personal. Aunque la mayoría de la gente cree en Dios, no todos coinciden en la manera como se lo representa o concibe.

- El $\mathbf{4 5 \%}$ cree en un Dios personal.

- El 30\% cree que existe una fuerza o espíritu superior.

- El 14\% no se inclina a ninguna de las alternativas anteriores. 
- Un 8\% no cree que exista Dios.

- Un 3\% no contesta.

- Las mujeres y los más viejos creen más en un Dios personal que los varones y los más jóvenes.

- Los de mayor educación creen más en una fuerza superior en contraste con los de menor educación que adhieren a un Dios personal.

- La idea de un Dios personal en más fuerte en África, con un $64 \%$.

- Lo mismo ocurre en América Latina, con un $64 \%$.

- En América del Norte con un $62 \%$.

- En el sudeste asiático con un $27 \%$.

- En Europa occidental con un $35 \%$.

- En la Argentina, el 72\% considera que hay un Dios personal, mientras que el $17 \%$ piensa que hay alguna clase de espíritu o fuerza superior.

1.5. ¿Existe una sola religión verdadera?

- La mayoría de la población del mundo, un $46 \%$, opinó que existen varias religiones verdaderas.

- Un 31\% afirmó que sólo una es verdadera.

- El 10\% no cree que alguna sea la verdadera.
- $\quad$ El $\mathbf{1 3 \%}$ no sabe o no contesta la pregunta.

- Los que enfatizan la idea de una única religión verdadera son las mujeres, los de mayor edad y los de educación primaria.

- En África y América Latina es donde más de cree en la verdad de una sola religión.

- En América del Norte es donde más se piensa que existen varias religiones verdaderas.

- En Europa se responde mayoritariamente que ninguna religión es verdadera.

- En la Argentina, la mitad expresa que hay una religión verdadera, en tanto el $35 \%$ considera que muchas son verdaderas.

\section{Realidad religiosa en países latinoamericanos}

La encuesta Millennium, de Gallup International, nos ha permitido aproximarnos a dar un vistazo general de la situación religiosa en el mundo, y de Argentina en el contexto Latinoamericano. Así, en cuanto a América Latina, considero necesario detenerme en datos cuantitativos adicionales que permitirán ofrecer mayor profundidad y certeza a nuestro presente análisis. Para tal efecto, tomo parte del trabajo realizado por Cristóbal Sifón (2010). 
2.1. Países más religiosos de América Latina.

- Bolivia con un $\mathbf{9 8 \%}$ de sus habitantes que se declaran religiosos.

- Colombia con un $\mathbf{9 8 \%}$ de sus habitantes que se declaran religiosos.

- Ecuador con un $\mathbf{9 8 \%}$ de sus habitantes que se declaran religiosos.

2.2. País menos religioso de América Latina.

- Uruguay con un $\mathbf{7 4 \%}$ de sus habitantes que se declaran religiosos.

2.3. Fuera de Uruguay, todos los países latinos de Sudamérica, además de México, están sobre (o alrededor) el $\mathbf{9 5 \%}$ de población religiosa.

2.4. Situación religiosa en Centro América.

- Los países muestran cifras similares entre sí, y menores a las de Sudamérica.

- Todos los países tienen entre un $83 \%$ y un $90 \%$ de personas que se declaran religiosas.

- En Panamá el 95\% de la población es religiosa (Holland, 2008).

2.5. Situación religiosa de otros países de América Latina.
- En México, un 62\% de las personas afirma que "Dios realmente existe y no tengo dudas al respecto", mientras que sólo un $3 \%$ declara no creer en (ningún) Dios. Un $\mathbf{4 5} \%$ de los encuestados cree "definitivamente" en la vida después de la muerte (a lo que se suma un $\mathbf{2 8} \%$ que "probablemente" cree), un $\mathbf{5 1 \%}$ cree en el cielo (más $\mathbf{2 7} \%$ ) y un $\mathbf{4 8} \%$ (más $\mathbf{2 5 \%}$ ) en los milagros. Un $\mathbf{6 0} \%$ está de acuerdo (o "muy de acuerdo") en que existe un Dios que "se preocupa de cada ser humano personalmente"; para un $39 \%$ "la vida sólo tiene sentido porque Dios existe", y un $40 \%$ de los encuestados reza una vez al día o más (Instituto de mercadotecnia y opinión IMO, 2009).

- En Perú, una encuesta realizada por la Universidad de Lima muestra que un $96 \%$ de los limeños cree en Dios, mientras que un $\mathbf{8 9} \%$ profesa alguna religión (más del 99\% de ellos se declara cristiano). Un $\mathbf{7 2} \%$ de las personas declara rezar una vez al día o más y un $\mathbf{6 3} \%$ lee la Biblia, pero sólo un $\mathbf{2 5 \%}$ participa de actividades religiosas en su parroquia. Un $\mathbf{7 5 \%}$ de las personas cree que existen los ángeles y un $\mathbf{7 7 \%}$ cree en el diablo (2008). 
- En Argentina, en tanto, un 91\% de la población cree en Dios (además, un $\mathbf{4} \%$ contestó "duda / a veces"). Un $\mathbf{7 8 \%}$ de los argentinos reza en casa y un $\mathbf{4 3} \%$ lee la Biblia, aunque un $\mathbf{7 1} \%$ de las personas considera que sus hijos deben elegir su propia religión o creencia - un número muy alto (y dudoso), dadas las prácticas actuales (Mallimaci, 2008).

- En Chile, un 85\% se declara religioso, pero un $\mathbf{9 4 \%}$ "cree en Dios y no tiene duda de ello"; un 62\% reconoce a Dios como "tanto o más importante que mi familia", pero un $\mathbf{8 1} \%$ dice preferir que sus hijos decidan sus creencias por su cuenta, y no tratarían de influir demasiado en ello. Como último dato, un $\mathbf{7 5} \%$ de los chilenos, según esta encuesta, cree en los milagros; un $69 \%$ cree en la Virgen y un $61 \%$ cree en la vida después de la muerte (Pontificia Universidad Católica, Adimark, 2006).

Ahora que tenemos las cifras proporcionadas por la encuesta mundial de Gallup, y las demás encuestas de distintas entidades latinoamericanas, corresponde formular algunas preguntas: ¿Qué conclusión se puede sacar a partir de las cifras proporcionadas por las encuestas?, ¿existe realmente una crisis en la religión? ¿Es posible afirmar con certeza que la posmodernidad atenta contra las creencias y prácticas religiosas de las personas? ¿Se puede afirmar que la posmodernidad es omniabarcante en su pensamiento, en el marco de la coyuntura mundial, y de manera específica en el contexto de América Latina?

Bien, las preguntas formuladas tienen el objetivo de orientar nuestras conclusiones, y además poder aproximarse a la concepción que la posmodernidad posee sobre Dios.

Para responder más directamente a la segunda pregunta, ya que la primera la responderé al final, puedo decir que SÍ existe crisis religiosa, y también puedo responder que NO existe una crisis religiosa. $\mathrm{La}(\mathrm{s})$ respuesta(s) en este sentido son evidentes. Cuando se aprecian las cifras del continente africano, y las de América Latina, nos encontramos con una gran inclinación de las personas a la experiencia religiosa, una gran devoción y creencia en Dios; claramente eso no responde a una crisis en la religión. Sin embargo, cuando se observan las cifras de Europa occidental, el sudeste asiático, y en algunos casos de América del Norte, nos encontramos con una verdadera crisis de la religión. Por eso digo que Sí y NO existe crisis en la religión. En este contexto, me parece que nos enfrentamos a una ambigüedad, 
que por supuesto no permite emitir un veredicto sobre el tema de la crisis de la religión, o sencillamente aceptar que no estamos frente a una crisis general, sino más bien local, y esto se relaciona por lo que pueda ser entendido por posmodernidad y crisis religiosa.

Considero que esto es precisamente lo que aportan las encuestas referidas, ya que permiten ubicarse y además identificar, claro que parcialmente, la realidad de Dios, en diferentes contextos y, sin duda, algunos de ellos presentan una clara evidencia de crisis en la religión. Me parece que esto debe ser destacado:

- En el sudeste asiático hay un $77 \%$ de personas que no pertenecen a ninguna confesión.

- El 48\% de los europeos occidentales no practica nunca o casi nunca el culto.

- El 44\% de los orientales no practica nunca o casi nunca el culto.

- $\quad$ En el sudeste asiático y Europa solo el $48 \%$ de las personas da importancia a Dios en su vida.

- $\quad$ En el sudeste asiático, el 27\% de las personas tiene fe en una divinidad personal.

- $\quad$ En Europa occidental, el 35\% de las personas tiene fe en una divinidad personal.
- $\quad$ En Europa se responde mayoritariamente que ninguna religión es verdadera.

Los resultados expresados, de forma clara ponen de manifiesto la existencia de una crisis en la religión, propia de las "nuevas sociedades europeas" (Corbí, 2005: 14) $\mathrm{y}$ asiáticas.

Retomando la continuidad de las interrogantes planteadas más arriba, sí es posible afirmar que la posmodernidad afecta la religión;sin embargo, no es del todo omniabarcante en el contexto mundial, resintiéndose fundamentalmente en las sociedades industriales y postindustriales.

Así, la crisis de la religión se puede identificar y describir de manera más específica de la siguiente forma, por supuesto siguiendo los resultados de la encuesta Gallup:

a. Se aprecia una sociedad independizada de las confesiones religiosas, por lo tanto, desactualizada y desvinculada de la revelación de Dios, que se manifiesta en la Palabra y en el núcleo humano que se congrega en torno a la Palabra por convocatoria divina.

b. Se observa una sociedad ajena a las prácticas cultuales, que son propias de la religión; esto nos habla de una sociedad sin ritos, por lo tanto, sin tener la 
capacidad de la reactualización que posee toda fe en Dios, en el contexto de la experiencia primordial de cada tradición religiosa, sin duda es esto lo que proporciona el pleno sentido a quienes practican el culto.

c. Dios ya no es necesario para el ser humano y, si es así, no es para nada tema de discusión, ni mucho menos algo que le preocupe. El ser humano se ha erigido como plenamente autosuficiente.

d. Si Dios se considera un ser personal, es posible hablar de relación con ese Dios. Si ya la divinidad no es personal, entonces se hace imposible hablar de relación. En este sentido, el ser humano posmoderno es un ser sin relación con la divinidad, porque esta última no es personal. La humanidad ingresa a una esfera de introspección total, a un verdadero ensimismamiento.

e. La verdad ha sido divorciada de la religión, lo que significa que no debe buscarse en la religión, y por lo tanto Dios ya nada tiene que ver con la verdad.

De acuerdo con lo anterior, y ofreciendo una respuesta a nuestra primera pregunta del grupo de interrogantes formuladas más arriba, se puede concluir que la posmodernidad, propia de países industrializados, ha desplazado a Dios de la experiencia humana, transformándose en un tema agotado, que ni siquiera despierta la más mínima inquietud. A este respecto, Antonio Cruz observa que "por su parte el nihilismo, como negación de cualquier creencia religiosa, política o social, también ha arraigado fuertemente en el hombre contemporáneo contribuyendo a la atrofia espiritual que se observa hoy. Nietzsche lo profetizó acertadamente: 'describo lo que viene: el advenimiento del nihilismo. Lo que cuento es la historia de los dos próximos siglos'. Y en efecto así ha sido" (1996: 110, 111).

\section{Evaluación crítica, perspectivas de futuro de la teología y cuestiones conclusivas}

Realizar una evaluación crítica en un contexto de notable ambivalencia (a mi juicio, y en lo que se refiere a la posmodernidad, el/la lector/a siéntase libre en interpretar el término a la manera de Paul Eugen Bleuler), como claramente se aprecia en el pensamiento que la posmodernidad posee sobre Dios, es como querer recoger una cierta cantidad de mercurio que ha sido derramada. En otras palabras, nos encontramos frente a una realidad de alta complejidad. Considero que en la presente evaluación debemos 
seguir con la apreciación del Sí y el NO. Sin embargo, y como una especie de oposición al habitual y recurrente juicio negativo que se le hace a la posmodernidad, me parece que la misma ha contribuido de manera notable, y esto eminentemente en el plano intelectual, al abandono del racionalismo como base epistemológica fundamental de su metodología de trabajo. Pero, ¿qué significado posee el abandono del racionalismo por parte de la posmodernidad en el plano de Dios y la religión?

En este sentido, me parece destacado el análisis que realiza el Dr. Fernando Canale, quien al respecto menciona:

El posmodernismo ha dejado claro que la razón no puede producir una verdad o explicación absoluta para las grandes preguntas que los seres humanos han formulado por siglos y que la filosofía y ciencia pretenden responder. Dicho de otra forma, el posmodernismo nos ha ayudado a entender que la razón no puede alcanzar verdades absolutas de las realidades cambiantes del Ser. Al limitar el poder de la razón como fundamento de la verdad absoluta, el posmodernismo deja el camino abierto para que la teología encuentre la verdad absoluta en la revelación bíblica de Dios (2007: 129).

Lo expresado por Canale plantea, sin duda, un verdadero desafío epistemológico y metodológico a la teología, y por supuesto al juicio que se pueda dirigir a la posmodernidad. En este contexto, la teología cristiana, si bien se ha detenido a reflexionar sobre el problema del ser humano posmoderno y a realizarle un urgente llamado a salir de esa situación nihilista, considero, y claro que llevando adelante el pensamiento de Canale, que pueda rescatar, por así decirlo, la confianza en Dios, en lo trascendente, en lo racionalmente (modernidad) inaccesible. Esta cuestión reviste una complejidad que se torna intelectualmente cautivante; parece que las experiencias y el tiempo llegan a trasponer profundamente las concepciones humanas. Así, las sociedades de la Europa Occidental y del sudeste asiático, han experimentado en el pasado (en pleno siglo XX), de manera profunda, las "bondades" de la modernidad, de la "infalible" razón (des)humana, volviéndose resultado, e incluso, digamos, superando aquella (sin)razón. En este sentido, la posmodernidad, en las mencionadas sociedades se vive y se llega a interpretar como una cuestión que expresa la liberación de esa razón que resultó ser de carácter suicida. En este sentido, ¿qué es lo que podemos juzgar de la posmodernidad?. Más adelante retomaré la pregunta.

Por otro lado, están las sociedades latinoamericanas, en donde presenciamos un escenario 
totalmente distinto. ¿Son estas sociedades modernas, por el hecho de conservarse fieles a las tradiciones religiosas? Me parece que es precisamente aquí donde surge una verdadera contradicción de enfoque y aproximación metodológicas. Esto porque "para superar el posmodernismo, la tradición se ha convertido en método. Cada teólogo trabaja dentro de su tradición" (Canale, 2002: 4), pero, ¿Qué se entiende por tradición, y qué relación posee ésta con la posmodernidad? En este contexto, el Dr. Fernando Canale dice que:

La tradición es un fenómeno histórico cognoscitivo. Es decir, por tradición nos referimos al proceso espacio-temporal a través del cual se forma el conocimiento humano. Dos son los niveles principales de la tradición, a saber, el proceso cognoscitivo y su resultado. Lo primero es una actividad, lo segundo una interpretación a la cual accedemos por medio de la palabra hablada o escrita. Mientras, la tradición como actividad tiene lugar en el presente, como interpretación escrita tiene lugar en el pasado cuando tuvo lugar la interpretación que el escrito comunica (6).

De acuerdo con lo expuesto por Canale, queda en evidencia que lo que se define por tradición como tal, encuentra su fuente de origen en el pensamiento posmoderno, ya "que toda teología es producto de la tradición escrita y vivida, es correcto decir, como afirma el posmodernismo, que todos pertenecemos a, y conocemos dentro de, una tradición específica" (6). En este sentido, Canale sigue el pensamiento de Hans-Georg Gadamer. De acuerdo con lo anterior, es posible apreciar la contradicción metodológica a la que me refería más arriba, es como superar la posmodernidad con la posmodernidad, al situarnos en el terreno de la tradición. De este modo, nuestras sociedades latinoamericanas resultan ser un cruce de multiplicidades de pensamientos que descargan toda su fuerza en las manifestaciones religiosas, en un constante acercarse a Dios, concibiéndolo como un ser cercano y personal, un Dios que aún puede vivir y celebrar en medio y con Latinoamérica.

Retomando lo anterior, la pregunta era la siguiente: ¿Qué es lo que podemos juzgar de la posmodernidad? Creo que de esta pregunta debe hacerse cargo la teología, ¿Por qué la teología? Porque me parece que la posmodernidad debe ser planteada, y por ende abordada, como un problema plenamente religioso, donde los protagonistas son Dios y los seres humanos. Juzgar una situación no es un ejercicio del todo fácil. Es que la posmodernidad ha alejado a los seres humanos de Dios, y también los ha acercado a Dios. Estamos frente a 
esa ambivalencia, a ese SÍ-NO. Sin embargo, hoy es posible decir en contra, y desde la posmodernidad, que Dios está por sobre todo, que trasciende, pero que también está en todos, que es inmanente.

A estas alturas de nuestra consideración, y por la extrema densidad del problema en estudio, considero que el mismo debe quedar abierto. Si Dios definitivamente es un misterio, aún lo continúa siendo en medio de la o las concepciones que el pensamiento humano pueda tener, como en este caso lo es el de la posmodernidad.

Finalmente, aún dentro de esa evidente ambivalencia, de ese
SÍ-NO, de esa gran crisis humana y de ese gran misterio divino, en donde el propio ser humano también resulta ser un desconocido para sí mismo, me parece que la interrogante planteada por Dietrich Bonhoeffer en su poema ¿Quién soy?, junto con su elocuente respuesta final, viene a descubrir al Dios real y al mismo tiempo al ser humano real, que la sociedad posmoderna debe urgentemente conocer. Debo agregar que esta última expresión la menciono en el más profundo sentido y significado hebreo del término, es decir, en tener una experiencia con Dios (von Rad, 1982: 124).

\section{¿Quién soy?}

¿Quién soy? Me dicen a menudo que salgo de mi celda

sereno, risueño y firme, como un noble de su palacio

¿Quién soy? Me dicen a menudo que hablo con los carceleros libre, amistoso y francamente como si mandase yo

¿Quién soy? Me dicen también que soporto los días de infortunio con indiferencia, sonrisa y orgullo, como alguien acostumbrado a vencer

¿Soy realmente lo que los otros dicen de mí?

¡O bien sólo lo que yo mismo sé de mí? 
Intranquilo, ansioso, enfermo, cual pajarillo enjaulado, pugnando por respirar, como si alguien me oprimiese la garganta,

hambriento de colores, de flores, de cantos de aves, sediento de buenas palabras y de proximidad humana, temblando de cólera ante la menor arbitrariedad o agravio, agitado por la espera de grandes cosas, impotente y temeroso por los amigos en la infinita lejanía, cansado y vacío para orar, pensar y crear, agotado y dispuesto a despedirme de todo.

¿Quién soy? ¿Éste o aquél?

¿Seré hoy éste, mañana otro?

¿Seré los dos a la vez?

¿Ante los hombres un hipócrita y ante mí mismo

un ser despreciable, quejumbroso y débil?

¿O bien lo que aún queda en mí se asemeja al ejército

batido que se retira desordenado ante la victoria

que tenía segura?

¿Quién soy?

Las preguntas solitarias se burlan de mí.

Sea quien sea, Tú me conoces, tuyo soy, joh Dios! (2004: 243, 244).

\section{Bibliografía}

Bonhoeffer, D. (2004). Resistencia y sumisión. Cartas y apuntes desde el cautiverio. Salamanca: Ediciones Sígueme.

Canale, F. (2002). Deconstrucción y teología: una propuesta metodológica. $D a$ varLogos, 1, 3-26.

Canale, F. (2007). Completando la teología adventista: el proyecto teológico adventista y su impacto en la iglesia parte II. DavarLogos, 6, 127-141.

Carballo, M. Religion in the world at the end of the millennium. Extraído el 29 de agosto de 2010 desde http://www. gallup-international.com/ContentFiles/millennium15.asp
Chiquete, D. (2003). "Latin American pentecostalisms and western postmodernism: reflections on a complex relationship". International Review of Mission, 92 (364), 29-39.

Chiquete, D. (2006). Silencio elocuente. Una interpretación teológica de la arquitectura pentecostal. San José: Universidad Bíblica Latinoamericana. Comunidad de Educación Teológica Ecuménica Latinoamericana y Caribeña, CETELA.

Corbí, M. (4-6/04/2005). La Espiritualidad en Una Sociedad Laica, Sin Sacralidades ni Creencias. Sociedades de Conocimiento: Crisis de la Religión y Retos a la Teología, Seminario de Teólogos y Teólogas. Costa Rica: Universidad 
Nacional, Escuela Ecuménica de Ciencias de la Religión.

Cruz, A. (1996). Postmodernidad. El Evangelio ante el desafío del bienestar. Terrassa: Editorial CLIE.

Follari, R. (2010). Reflexiones sobre posmodernidad, multiculturalismo y movimientos sociales en la Latinoamérica actual. Utopía y praxis latinoamericana, 43, 53-67. Extraído el 29 de agosto de 2010 desde http://www.revistas.luz.edu.ve/index.php/upl/article/ viewFile/4867/4735

Holland, C. L. (2008). Table of statistics on religious affiliation in the Americas and the Iberian Peninsula. Extraído el 29 de agosto de 2010 desde http://www. prolades.com/amertbl06.htm

Hong, I. S. (2001). ¿Una iglesia posmoderna? En busca de un modelo de iglesia y misión en la era posmoderna. Buenos Aires: Kairós Ediciones.

Instituto de mercadotecnia y opinión IMO (2009). Encuesta nacional del IMO en México sobre religión. Extraído el 29 de agosto de 2010 desde http:// www.imocorp.com.mx/Inicio/Estudios/08-09/IMO_08-09.swf

Mallimaci, F. (2008). Primera encuesta sobre creencias y actitudes religiosas en Argentina. Extraído el 29 de agosto de 2010 desde http://edant.clarin.com/ diario/2008/08/27/um/encuesta1.pdf

Pereyra, M. y Espinosa, E. (2000). La posmodernidad desde la perspectiva profética. Libertador San Martín: Bienestar Psicológico Editorial.

Pontificia Universidad Católica, Adimark, (2006). Encuesta nacional bicentenario. Extraído el 29 de agosto de 2010 desde http://www.emol.com/ noticias/documentos/pdfs/encuesta bicentenario211006.jpg2.pdf

Roa, A. (1991). La extraña figura antropológica del hombre de hoy. Santiago de Chile: Editorial Universitaria.

Sifón, C. (2010). La religión en América Latina... y en el ser humano. Extraído el 29 de agosto de 2010 desde http://1skeptikoi.blogspot.com/2010/08/lareligion-en-america-latina.html

Universidad de Lima (2008). Estudio 428 II. Encuesta sobre religiosidad. Provincia de Lima y región Callao. Sábado 4 y domingo 5 de octubre de 2008. Extraído el 29 de agosto de 2010 desde http://www.ulima.edu.pe/webulima. nsf/default/F598031D89943F2F0525 6E630017BD4C/\$file/barometro_social_oct_2008.pdf

Vásquez R. A. (2008). Zygmunt Bauman: Modernidad Líquida y Fragilidad Humana. Nómadas, 19. Extraído el 6 de febrero de 2010 desde http://redalyc. uaemex.mx/redalyc/src/inicio/ArtPdfRed.jsp?iCve $=18101917 \#$

Viera, J. C. (1990). La iglesia y el mundo. Una perspectiva adventista de la misión de la iglesia en el contexto latinoamericano. Buenos Aires: Ediciones SALT.

von Rad, G. (1982). El libro del Génesis. Salamanca: Ediciones Sígueme.

Yúdice, G. (1989). ¿Puede hablarse de posmodernidad en América Latina? Revista de crítica literaria latinoamericana, 29, 105-128. 